\title{
A New Resource for Research and Risk Analysis: The Updated European Food Safety Authority Database of Xylella spp. Host Plant Species
}

\author{
Alice Delbianco, ${ }^{1}$ Ewelina Czwienczek, ${ }^{1, \dagger}$ Marco Pautasso, ${ }^{1}$ Svetla Kozelska, ${ }^{1}$ Mario Monguidi, ${ }^{2}$ and \\ Giuseppe Stancanelli ${ }^{1}$ \\ ${ }^{1}$ Animal and Plant Health Unit, European Food Safety Authority, Parma, Italy \\ ${ }^{2}$ Evidence Management (DATA) Unit, European Food Safety Authority, Parma, Italy
}

\begin{abstract}
Following a series of requests for scientific advice from the European Commission starting in 2013, the European Food Safety Authority (EFSA) conducted a pest risk assessment and created a comprehensive Xylella fastidiosa host plant database. The last update of the database, published in September 2018, includes information on host plants of both $X$. fastidiosa and $X$. taiwanensis, together with details on botanical classification, infection conditions, geographic location, pathogen taxonomy including information on subspecies, strain and sequence type, detection techniques, and tolerant/resistant response of the plant. This updated database of host plants of Xylella spp. reported worldwide provides a key tool for risk management, risk assessment, and research on this generalist bacterial plant pathogen.
\end{abstract}

\section{Database Announcement}

Xylella fastidiosa is a generalist plant-pathogenic bacterium (Almeida and Nunney 2015) causing numerous plant diseases worldwide such as Pierce's disease of grapes, bacterial leaf scorch of shade trees and oleander leaf scorch in North America, and citrus variegated chlorosis in Brazil. In Taiwan, a leaf scorch disease of pear was described in association with a fastidious bacterium originally designated as a strain of $X$. fastidiosa (Leu and Su 1993), which was later shown to be genetically distant from other $X$. fastidiosa strains and thus classified as a novel species, $X$. taiwanensis (Su et al. 2016). In 2013, the identification of olive trees affected by $X$. fastidiosa in southern Italy represented the first record of an outbreak of this pathogen under field conditions in the European Union (EU) (Saponari et al. 2013). This first report was then followed by additional outbreaks in France and Spain (Denancé et al. 2017; Olmo et al. 2017). The European Commission requested the European Food Safety Authority (EFSA) to provide scientific assistance on this matter. In January 2015, EFSA published a pest risk assessment of $X$. fastidiosa for the EU territory (EFSA PLH Panel 2015) that included a list of the known host plant species of $X$. fastidiosa collected through a literature search. EFSA was then given the task to periodically update the database of $X$. fastidiosa host plants, and in 2016 an electronic version was published (EFSA 2016). For the period 2016 to 2020, EFSA was requested to further update this database by taking into account the different subspecies, strains, and European isolates of $X$. fastidiosa, together with information on tolerant/resistant plant varieties and negative results of diagnostic tests.

The process for updating the host plant database of Xylella spp., taking into account both $X$. fastidiosa and $X$. taiwanensis, was divided into the following steps: (i) an extensive literature

\footnotetext{
${ }^{\dagger}$ Corresponding author: E. Czwienczek; E-mail: alpha@efsa.europa.eu
}

The positions and opinions presented in this article are those of the authors alone and are not intended to represent the views or any official positions of their institutions.

Accepted for publication 7 November 2018.

(C) 2019 The American Phytopathological Society 
search to identify the relevant references; (ii) the selection of the retrieved studies based on titles, abstracts, and full-text; (iii) the extraction of the relevant information from the selected references; (iv) and data analysis and reporting.

The literature search was conducted in 2017 and 3,595 references were obtained, supplemented by additional information provided by scientific experts and national authorities. On the whole, 853 publications were selected for data extraction and 8,391 data extraction forms were filled with data covering botanical classification of the plant according to the updated taxonomy from the European and Mediterranean Plant Protection Organization (EPPO) global database (EPPO 2018), infection conditions and location of the infected plant, geographic coordinates, isolate characterization (Xylella species, subspecies, disease, strain, and multilocus sequence type), methods of detection, and information about the tolerant/resistant response of the plant.

Data reporting was designed to categorize Xylella host plant species based on the number and type of detection methods applied for each finding. Different combinations of detection methods were considered.

A. Plant species positive with at least two detection methods (out of symptom observation on the test plant in experimental vector transmission, enzyme-linked immunosorbent assay (ELISA), other immunological techniques, polymerase chain reaction (PCR)-based methods, sequencing, or culturing) or positive with sequencing or culturing.

B. The same as category A, but also including microscopy.

C. Plant species positive with at least one detection method (out of symptom observation on the test plant in experimental vector transmission, ELISA, other immunological techniques, PCR-based methods, sequencing, or culturing).

D. The same as category $C$, but also including microscopy.

E. All plant species reported positive, regardless of the detection method (positive records but without the detection method specified, symptom observations, microscopy, symptom observation on the test plant in experimental vector transmission, ELISA, other immunological techniques, PCR-based methods, sequencing, or culturing).

An example of data reporting is presented in Table 1, in which the number of host plant species (according to categories A, B, C, D, and E) infected by different $X$. fastidiosa subspecies in artificial, natural, and unspecified conditions is shown. The complete lists of plant species are available in the database and scientific report (EFSA 2018), both of which are open access.

$X$. taiwanensis is not included in Table 1 because up until now it was reported only in naturally infected Pyrus pyrifolia in Taiwan.

A detailed genetic characterization of Xylella spp. (such as species, subspecies, strains, and multilocus sequence type) as well as the tolerant/resistant host status of the plant species or variety are included in the current version of the database, with special categories and extensive comments.

This updated Xylella spp. host plant database was released in September 2018 together with a detailed report (EFSA 2018). The raw data and related metadata are published in Zenodo in the EFSA Knowledge Junction community: https://zenodo.org/record/1339344. Interactive reports are available at the following link: https://www.efsa.europa.eu/en/microstrategy/xylella.

Table 1. Number of host plant species reported infected by different subspecies of Xylella fastidiosa under artificial, natural, or unspecified conditions ${ }^{\mathrm{a}}$, according to confirmation categories $\mathrm{A}, \mathrm{B}, \mathrm{C}, \mathrm{D}$, and $\mathrm{E}^{\mathrm{b}}$

\begin{tabular}{|c|c|c|c|c|c|c|c|c|c|c|c|c|c|c|c|}
\hline \multirow[b]{2}{*}{$X$. fastidiosa subspecies } & \multicolumn{5}{|c|}{ Artificial } & \multicolumn{5}{|c|}{ Natural } & \multicolumn{5}{|c|}{ Unspecified } \\
\hline & A & B & C & D & $\mathbf{E}$ & A & B & C & D & E & A & B & C & D & $\mathbf{E}$ \\
\hline fastidiosa & 35 & 35 & 41 & 41 & 42 & 32 & 32 & 32 & 32 & 32 & 3 & 3 & 3 & 3 & 3 \\
\hline fastidiosa/sandyi & 0 & 0 & 0 & 0 & 0 & 2 & 2 & 2 & 2 & 2 & 0 & 0 & 0 & 0 & 0 \\
\hline multiplex & 8 & 8 & 11 & 11 & 11 & 108 & 108 & 116 & 116 & 116 & 10 & 10 & 11 & 11 & 11 \\
\hline pauca & 7 & 7 & 13 & 13 & 13 & 41 & 41 & 43 & 43 & 43 & 1 & 1 & 1 & 1 & 1 \\
\hline sandyi & 3 & 3 & 3 & 3 & 3 & 6 & 6 & 7 & 7 & 7 & 0 & 0 & 0 & 0 & 0 \\
\hline
\end{tabular}

a Artificial inoculation includes both mechanical inoculation and vector transmission; natural infection includes all records of host plants found during survey or research activities; and unspecified infection includes all cases where no details on the type of infection methods were reported.

${ }^{b}$ Categories A through E represent progressively less stringent confirmation criteria as described in detail in the text. 
The EFSA database of Xylella spp. host plant species reported worldwide is a key tool for risk management, risk assessment and research on this generalist bacterial plant pathogen, and is expected to be kept up-to-date as new relevant information becomes available.

\section{Acknowledgments}

We thank EFSA staff members (A. Baù, C. Gardi, T. Kaluski, O. Mosbach-Schulz, I. Muñoz Guajardo, L. Pasinato, and S. Tramontini), external contractor M. N. Quan from BV-Tech for developing the interactive reports, and experts for scientific advice (R. Almeida, C. Bragard, T. Candresse, M.-A. Jacques, J. R. Spotti Lopes, and L. Nunney).

\section{Literature Cited}

Almeida, R. P. P., and Nunney, L. 2015. How do plant diseases caused by Xylella fastidiosa emerge? Plant Dis. 99:1457-1467.

Denancé, N., Legendre, B., Briand, M., Olivier, V., de Boisseson, C., Poliakoff, F., and Jacques, M.-A. 2017. Several subspecies and sequence types are associated with the emergence of Xylella fastidiosa in natural settings in France. Plant Pathol. 66: 1054-1064.

EFSA (European Food Safety Authority). 2016. Scientific report on the update of a database of host plants of Xylella fastidiosa: 20 November 2015. EFSA J. 14:4378.

EFSA (European Food Safety Authority). 2018. Scientific report on the update of the Xylella spp. host plant database. EFSA J. 16:5408.

EFSA PLH Panel (EFSA Panel on Plant Health). 2015. Scientific opinion on the risks to plant health posed by Xylella fastidiosa in the EU territory, with the identification and evaluation of risk reduction options. EFSA J. 13:3989.
EPPO. 2018. EPPO Global Database. https://gd.eppo.int

Leu, L. S., and Su, C. C. 1993. Isolation, cultivation, and pathogenicity of Xylella fastidiosa, the causal bacterium of pear leaf scorch disease in Taiwan. Plant Dis. 77: 642-646.

Olmo, D., Nieto, A., Adrover, F., Urbano, A., Beidas, O., and Juan, A., et al:et al. 2017. First detection of Xylella fastidiosa infecting cherry (Prunus avium) and Polygala myrtifolia plants, in Mallorca Island, Spain. Plant Dis. 101:1820.

Saponari, M., Boscia, D., Nigro, F., and Martelli, G. P. 2013. Identification of DNA sequences related to Xylella fastidiosa in oleander, almond and olive trees exhibiting leaf scorch symptoms in Apulia (Southern Italy). J. Plant Pathol. 95: 668.

Su, C.-C., Deng., W.-L., Jan, F.-J., Chang, C.-J., Huang, H. Shih, H.-T., and Chen, J. 2016. Xylella taiwanensis sp. nov., causing pear leaf scorch disease. Int. J. Syst. Evol. Microbiol. 66:4766-4771. 